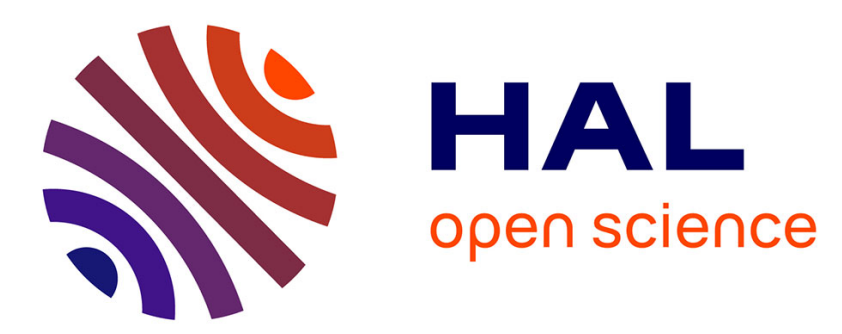

\title{
Comparison of SiC Thyristors with Differently Etched JTEs
}

Gontran Pâques, Sigo Scharnholz, Nicolas Dheilly, Dominique Planson, Rik W. de Doncker

\section{- To cite this version:}

Gontran Pâques, Sigo Scharnholz, Nicolas Dheilly, Dominique Planson, Rik W. de Doncker. Comparison of SiC Thyristors with Differently Etched JTEs. Materials Science Forum, 2012, 717-720, pp.1167 - 1170. 10.4028/www.scientific.net/MSF.717-720.1167 . hal-01627763

\section{HAL Id: hal-01627763 https://hal.science/hal-01627763}

Submitted on 18 Jan 2019

HAL is a multi-disciplinary open access archive for the deposit and dissemination of scientific research documents, whether they are published or not. The documents may come from teaching and research institutions in France or abroad, or from public or private research centers.
L'archive ouverte pluridisciplinaire HAL, est destinée au dépôt et à la diffusion de documents scientifiques de niveau recherche, publiés ou non, émanant des établissements d'enseignement et de recherche français ou étrangers, des laboratoires publics ou privés. 


\title{
Comparison of SiC thyristors with differently etched JTEs
}

\section{Gontran Pâques ${ }^{1,3, a}$, Sigo Scharnholz ${ }^{1, b, *}$, Nicolas Dheilly, ${ }^{2, c}$, Dominique Planson $^{2, \mathrm{~d}}$, and Rik W. De Doncker ${ }^{3, \mathrm{e}}$}

\author{
${ }^{1}$ French-German Research Institute of Saint Louis (ISL), BP 70032, 68301 Saint Louis, France \\ ${ }^{2}$ Ampère Laboratory, UMR-5005, INSA de Lyon, 20 av. A. Einstein, 69621 Villeurbanne, France \\ ${ }^{3}$ E.ON-ERC, RWTH Aachen University, Mathieustr. 6, 52074 Aachen, Germany \\ agontran.paques@rwth-aachen.de, ${ }^{\mathrm{b}}$ sigo.scharnholz@isl.eu, ${ }^{c}$ nicolas.dheilly@inas-lyon.fr, \\ dominique.planson@insa-lyon.fr, ${ }^{\mathrm{e}}$ dedoncker@eonerc.rwth-aachen.de *corresponding author
}

Keywords: silicon carbide, thyristor, GTO, termination, RIE, ion implantation

\begin{abstract}
This paper presents results attained with SiC GTO thyristors terminated by a single step and a graded etched JTE. The comparison of both types of devices reveals no significant difference in the on-state and switching characteristics but a higher blocking capability of some thyristors with the latter kind of termination. The best devices showed a forward breakdown voltage of nearly $6 \mathrm{kV}$, which is a distinct progress as against previous results of thyristors with a graded etched JTE. Furthermore, such GTO thyristors have been characterized dynamically for the first time.
\end{abstract}

\section{Introduction}

One of the most critical aspects when fabricating silicon carbide thyristors, to be utilized for instance in pulsed power applications [1, 2], is the termination. To reach high blocking voltages, nowadays, an implanted junction termination extension (JTE) is commonly used [2, 3]. The ion implantation and following high temperature annealing process can cause crystal damage and surface roughness, respectively, which affect the performance of the fabricated devices. Etched terminations are therefore an attractive alternative. Moreover, etched terminations are less laborious and less cost-intensive. For three terminal bipolar SiC devices, a very promising termination is an etched JTE based on the intermediately doped base layer underneath the anode. Such kind of termination has been published first for BJTs by others [4] and then by us for thyristors [5]. In the latter publication, the concept of a graded etched (GE) JTE was presented using finite element simulations. Furthermore, first electrical characteristics of GTO thyristors with a $35 \mu \mathrm{m}$ drift layer were shown. In the present paper, we report more detailed results of GTO thyristors with a $60 \mu \mathrm{m}$ drift layer and compare devices having a single step termination with others terminated by a 3-step GEJTE.

\section{Device Design and Fabrication}

In this paper two samples are considered. The thyristor devices on these two samples differ only in the kind of their termination. Devices on sample 1 are terminated by a single step and devices on sample 2 have a 3-step JTE. Details on the device design and fabrication are given in the following.

Structure and Layout. The employed $\mathrm{p}^{+} \mathrm{np}{ }^{-} \mathrm{pn}$ structure shown in Fig. 1 is typical for asymmetric SiC GTO thyristors. The five epilayers were grown on an $8^{\circ}$-off n-type $4 \mathrm{H}$-SiC wafer from Cree, Inc. With $3 \mu \mathrm{m}$, the n-base layer is relatively thick, since originally the wafer (without $\mathrm{p}^{+}$anode epi-layer) was designated for planar thyristors with an implanted anode [6]. As in [5] the n-base layer was used to form a 3-step JTE at the periphery of the devices on one sample (no. 2). On the other sample (no. 1) the devices are terminated by a single mesa etch, which is equivalent to a single step JTE. The critical forward breakdown voltage of the plane-parallel junction, simulated with the T-CAD software Sentaurus ${ }^{\mathrm{TM}}$ and using the ionization coefficients from [8], amounts to $8.1 \mathrm{kV}$. 
The devices layout shown in Fig. 2 reveals the three $50 \mu \mathrm{m}$ wide JTE steps surrounding the active area. Discernible is the second metallization level which consists of a gate stripe in the middle of two bigger anode contacts areas. While the gate stripe is necessary to interconnect the gate fingers by feedthroughs, the anode fingers are already interconnected by the first metallization level underneath the passivation layer. The gate and anode fingers have equal width of 30 and $60 \mu \mathrm{m}$, respectively. The active devices area is $4.86 \times 10^{-3} \mathrm{~cm}^{2}$ for all devices considered in this paper.

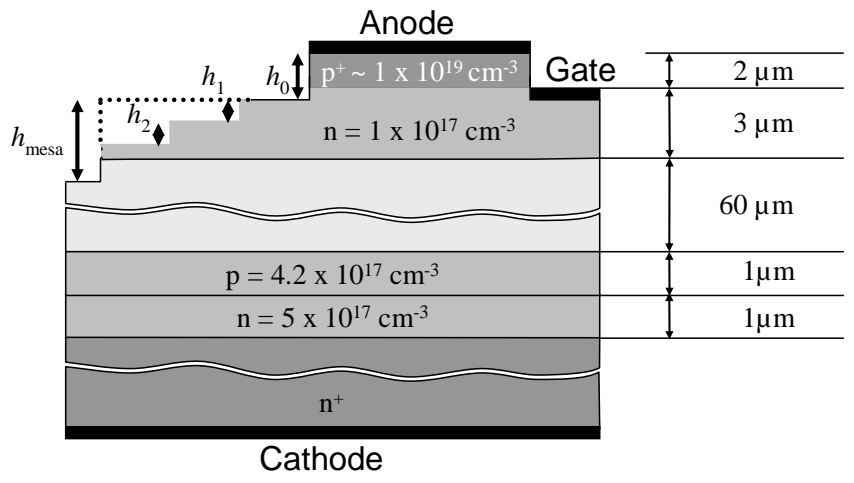

Fig. 1: Schematic cross-section of the employed thyristor structure with GEJTE.

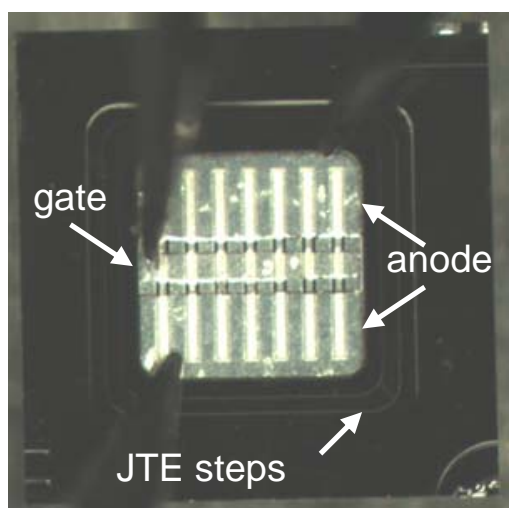

Fig. 2: Top view of a fabricated SiC GTO thyristor die (1.4 by $1.4 \mathrm{~mm}^{2}$ ) with an etched 3-step JTE.

Processing. The two samples considered in this paper have been processed together. Each sample is about $1 \mathrm{~cm}^{2}$ in size and comprises more than 30 GTO thyristors with identical footprint (Fig. 2). A set of seven masks was used to fabricate the devices. All etching steps were done with a reactive ion etching (RIE) process. First, the gate/anode structure $\left(h_{0}\right)$ was etched to a depth of $3.9 \mu \mathrm{m}$ using a nickel mask. Despite of possible metal contaminations this was done for reasons of selectivity and lateral resolution. The following etching steps for the mesa $\left(h_{\text {mesa }}\right)$ and the JTE were done using photo resist masks. Initially, the mesa was defined by an etching of $2.2 \mu \mathrm{m}$. During the subsequent two etching runs, on one sample, the mesa was protected the same way, and on the other, smaller masks were used to define the two additional JTE steps, $h_{1}$ and $h_{2}$, finally measuring $390 \mathrm{~nm}$ and $426 \mathrm{~nm}$, respectively. Thus, the total mesa height is identical on both samples and amounts to approximately $3 \mu \mathrm{m}$.

After etching the samples were thoroughly cleaned and then ohmic contacts were realized separately for surfaces on $\mathrm{n}$ - and p-type SiC. For the contacts on the gate and the cathode, Ni was used and annealed at $1100^{\circ} \mathrm{C}$. For the contacts on the anode, a Ni/Ti/Al tri-layer was used and annealed at $850^{\circ} \mathrm{C}$. Thereafter a $1 \mu \mathrm{m}$ thick $\mathrm{Al}$ based over-metallization was formed. $\mathrm{Next}, \mathrm{SiO}_{2}$ was deposited by PECVD to passivate the surface and to isolate the first from the second metallization level. After oxide opening, a second metallization level was formed with $\mathrm{Al}$ as shown in Fig. 2.

Packaging. After front end processing and preliminary electrical characterization, the two samples have been cut into dies measuring 1.4 by $1.4 \mathrm{~mm}^{2}$ (Fig. 2). Some of these dies have then been attached to a PCB type of support to facilitate the electrical connection of the three electrodes. While the cathode contact was soldered, the upper contacts have been bonded using $50 \mu \mathrm{m} \mathrm{Al}$ wires, a single one for the gate and up to three on each anode pad. The final packaging, which does not yet use any encapsulation, is shown in Fig. 5.

\section{Electrical Characterization}

Blocking Characteristics. The blocking capability of the devices has been measured before dicing with a vacuum probe station at a pressure of less than $10 \mathrm{mPa}$. The forward blocking and reverse 
characteristics of those 5 thyristors on each sample presenting the highest blocking voltages are shown in Fig. 3. Obviously, the best thyristors with GEJTE have a distinctively higher forward breakdown voltage and a slightly lower leakage current level than their counterparts with just a single step termination. For both types of devices, up to about $-2 \mathrm{kV}$ the leakage current rests below the detection limit $\left(10^{-10} \mathrm{~A}\right)$ of the measuring instrument.

The highest forward breakdown voltage amounts to $6 \mathrm{kV}$, which is just $75 \%$ of the ideal value. This is most likely to be explained by the two lower JTE steps $\left(h_{1}\right.$ and $\left.h_{2}\right)$ being too high and thus lowering the JTE dose too much. The gain of these two steps inherently depends on the initial JTE dose, defined by $h_{0}$, which is intentionally chosen higher than the optimal value. The breakdown voltage limit of $4 \mathrm{kV}$, presented by devices with just a mesa etch, indicates that already the first JTE step $h_{0}$, defining this initial dose, is merely $100 \mathrm{~nm}$ lower than the value which is necessary to arrive at an optimal dose of about $1 \times 10^{13} \mathrm{~cm}^{-2}$. Therefore, it is likely that the subsequent JTE steps overshoot the mark and could not optimally contribute to increase the termination efficiency.

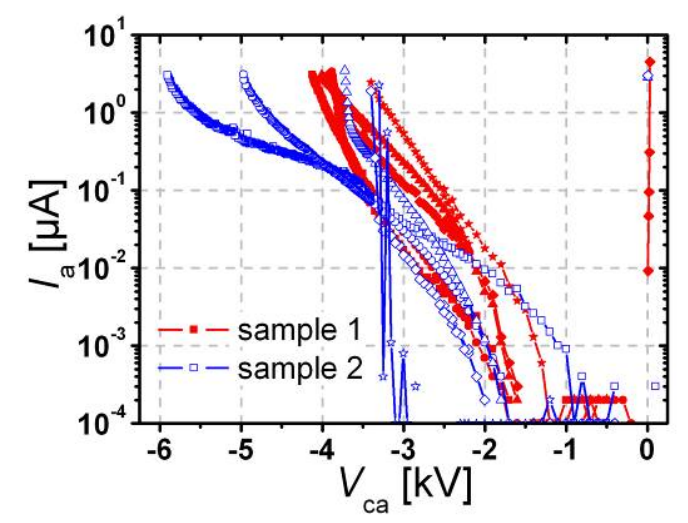

Fig. 3. Comparison of the forward and reverse blocking characteristics of asymmetric SiC GTO thyristors with single step termination (sample 1) and with a 3-step GEJTE (sample 2).

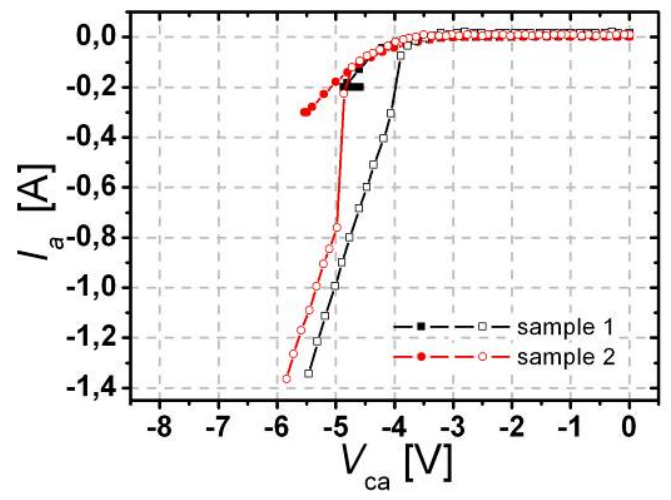

Fig. 4. On-state characteristics of the fabricated SiC thyristors measured with an SMU before (full symbols) and with a curve tracer after dicing and bonding (open symbols).

On-state Characteristics. On-state characteristics of devices from the two samples are shown in Fig. 4. In each case two curves are depicted: one (full symbols) taken before dicing, using a probe station and an SMU, and another one (open symbols) originating from a bonded die measured with a curve tracer (Fig. 5). As expected, before dicing thyristors on both samples show a comparable on-state voltage drop. The obvious discrepancy for the two packaged devices is most likely attributed to problems with the anode bonding connection and not to differences in the termination. The maximum current of roughly 1.4 A corresponds to a current density of $288 \mathrm{~A} / \mathrm{cm}^{2}$ in the active area of the device. The application of this load did not reveal any obvious stability problems.

Switching Characteristics. Fig. 6 shows switching characteristics of the same two bonded SiC thyristor dies of which Fig. 4 depicts the on-state characteristics measured with a curve tracer. Given are the waveforms of the anode current $I_{\mathrm{a}}$, the cathode anode voltage $V_{\text {ca }}$, and the gate current $I_{\mathrm{g}}$. The limitations of these first dynamic characteristics concerning the on-state current $(100 \mathrm{~mA})$ and the blocking voltage $(500 \mathrm{~V})$ were due to both precaution and the used test set-up. The gate pulse applied in the experiments depicted in Fig. 6 was adjusted so that switching on and off were only just possible. The gate pulse width was set to 500 ns for turn-on and $10 \mu$ for turn-off. For both devices a current of at least $15 \mathrm{~mA}$ and $30 \mathrm{~mA}$ was necessary to initiate turn-on and gate turnoff, respectively. The overshot of the gate current in case of sample 2 is attributed to a current path parallel to the anode gate diode, probably originating from isolation problems caused by wire bonding. The turn-on delay time was $350 \mathrm{~ns}$ and $1.1 \mu$ s for sample 1 and 2, respectively. For a gate current of $30 \mathrm{~mA}$ the turn-off delay amounted to $3.8 \mu$ s and $1 \mu$ s for sample 1 and 2 , respectively. 


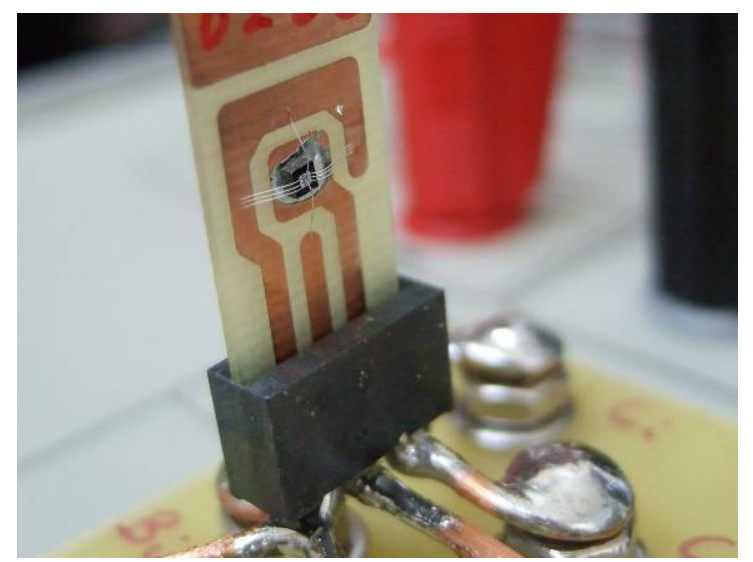

Fig. 5: SiC GTO thyristor with a 3-step JTE attached to a PCB based package and bonded with $50 \mu \mathrm{m} \mathrm{Al}$ wires.

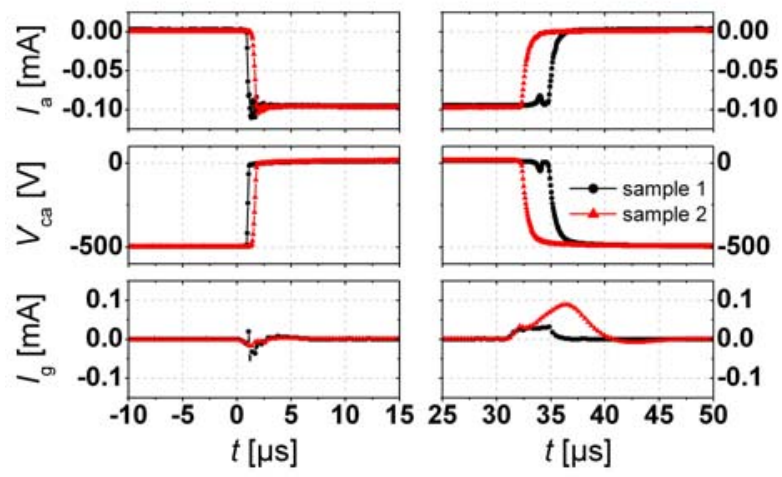

Fig. 6: Switching waveforms of bonded SiC thyristor dies originating from the two samples under investigation.

\section{Conclusions}

In conclusion, asymmetric SiC GTO thyristors with two differently etched terminations have been fabricated based on an epiwafer with a $60 \mu \mathrm{m}$ drift layer. Thyristors terminated with a 3-step JTE show a forward blocking voltage of up to $6 \mathrm{kV}$, which is distinctively higher than the maximum value of equally processed devices with a single step termination. The termination efficiency of the 3-step JTE reaches just $75 \%$ which is attributed to a deficiency of the applied etching process. Apart from that, the breakdown voltage of thyristors with a single step termination corresponds quite well to the expected value of $4 \mathrm{kV}$. Both types of devices show comparable on-state and switching characteristics. The on-state voltage drop is in the order of $5 \mathrm{~V}$ for a current density of $100 \mathrm{~A} / \mathrm{cm}^{2}$, which is comparable to SiC thyristors with an implanted termination. The devices can be switched on and off using reasonable gate pulses. The noticeable differences observed in the turn-off characteristics of the two specific devices depicted in this paper do rather result from processing defects than from differences in their termination. More experiments are necessary to evaluate the dynamic behavior and the switching capabilities of the devices.

\section{References}

[1] S. Scharnholz, B. Vergne, J.-P. Konrath, G. Pâques, and V. Zorngiebel, Pulse current characterization of SiC GTO thyristors, Material Science Forum 679-680 (2011) 682.

[2] A.K. Agarwal, C. Capell et al., $9 \mathrm{kV}, 1 \mathrm{cmx} 1 \mathrm{~cm}$ SiC super GTO technology development for pulsed power, Proc. of Int. IEEE Pulsed Power Conference (2009) 264.

[3] X. Xu et al., Proc. of Power Electronics Specialists Conference, pp. 1 - 5, (2006)

[4] R. Ghandi et al., Implantation-free low on-resistance 4H-SiC BJTs with common emitter current gain of 50 and high blocking capability, Materials Science Forum 615-617 (2009) 833.

[5] G. Pâques, N. Dheilly, D. Planson, R.W. De Doncker, and S. Scharnholz, Graded etched junction termination for SiC thyristors, Materials Science Forum 679-680 (2011) 457.

[6] P. Brosselard, Conception, réalisation et caractérisation d'interrupteurs (thyristors et JFETs) haute tension (5 kV) en carbure de silicium, PhD dissertation, INSA de Lyon, 2004.

[7] A. Konstantinov et al. Journal of Electronic Materials, vol. 27, pp. 335-341, (1998) 